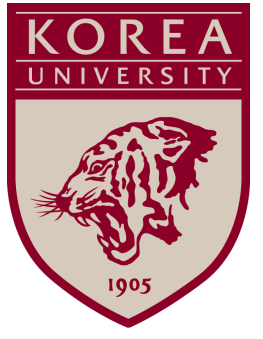

Discussion Paper Series

No. 1302

May 2013

\title{
Exchange Rate Predictability and a Monetary Model with Time-varying Cointegration Coefficients
}

\author{
Cheolbeom Park and Sookyung Park
}

The Institute of Economic Research - Korea University

Anam-dong, Sungbuk-ku, Seoul, 136-701, South Korea, Tel: (82-2) 3290-1632, Fax: (82-2) 928-4948

Copyright (c) 2013 IER. 


\title{
Exchange Rate Predictability and a Monetary Model with Time-varying Cointegration Coefficients ${ }^{1}$
}

\author{
Cheolbeom Park \\ Korea University \\ and \\ Sookyung Park \\ Korea University
}

April 2013

\begin{abstract}
Many studies have pointed out that the underlying relations and functions for the monetary model (e.g. the PPP relation, the money demand function, monetary policy rule, etc.) have undergone parameter instabilities and that the relation between exchange rates and macro fundamentals are unstable due to the shift in the economic models in foreign exchange traders' views or the scapegoat effect in Bacchetta and van Wincoop (2009). Facing this, we consider a monetary model with time-varying cointegration coefficients in order to understand exchange rate movements. We provide statistical evidence against the standard monetary model with constant cointegration coefficients but find favorable evidence for the time-varying cointegration relationship between exchange rates and monetary fundamentals. Furthermore, we demonstrate that deviations between the exchange rate and fundamentals from the time-varying cointegration relation have strong predictive power for future changes in exchange rates through in-sample analysis, out-of-sample analysis, and directional accuracy tests.
\end{abstract}

Key Words: Exchange rate, Monetary model, Predictability, Time-varying cointegration

JEL Classification: F31, F47

\footnotetext{
${ }^{1}$ We are grateful to an anonymous referee for valuable comments. We also thank seminar participants at Korea University and Kyung Hee University for helpful comments and discussions. However, all remaining errors are ours.

Cheolbeom Park (corresponding author): Department of Economics, KoreaUniversity, Anam-dong, Seongbuk-gu, Seoul, Korea 136-701. (TEL: +82-2-3290-2203. Fax: +82-2-3290-2200. E-mail: cbpark_kjs@korea.ac.kr).

Sookyung Park: Department of Economics, KoreaUniversity, Anam-dong, Seongbuk-gu, Seoul, Korea 136701. (E-mail: $\underline{\text { soo62@korea.ac.kr) }}$
} 


\section{Introduction}

Although the exchange rate shows simply the rate at which one country's currency trades for another country's currency, its movements have been a long-standing enigma to economists. Many theoretical models such as Dornbusch (1976) have been developed, but their empirical validity in predicting exchange rates has been known to be quite limited (Meese and Rogoff (1983)). Unlike Meese and Rogoff (1983), Mark (1995) and Chinn and Meese (1995) reported evidence that the current deviation of the exchange rate from fundamentals of the monetary model has predictive power for future changes in the exchange rate. After making corrections in the statistical methodology and extending the sample periods, however, Kilian (1999) and Berkowitz and Gorgianni (2001) demonstrated that the results in Mark (1995) or Chinn and Meese (1995) were not robust, which implies that the result from Meese and Rogoff (1983) still holds (Rogoff (2009)).

Although economists have not yet reached a consensus on the economic model to understand movements of the exchange rate, we attempt a monetary model with timevarying cointegration coefficients to explain movements of the exchange rate. Previous studies (e.g. Mark (1995), Kilian (1999), etc.) imposed restrictions on coefficients in the money demand function, purchasing power parity relation (PPP), interest rate parity relation, and others to derive a cointegration relation between the exchange rate and fundamentals from the monetary model. However, Kilian (1999) showed that it is difficult to overcome the random walk model in forecasting the exchange rate based on this restricted monetary model. The failure of the monetary model with constant cointegration coefficients might be due to the limit in regards to the monetary model. But those firm restrictions on the coefficients might also be responsible for the failure of the monetary model rather than the nature of the model.

There are reasons why those cointegration coefficients might vary over time. 
Various studies have found that underlying functions and relations of the monetary model have parameter instabilities. Bierens and Martin (2010) showed that there exists a timevarying cointegration relation among variables for the PPP hypothesis. Stock and Watson (1993) demonstrated that the money demand function has unstable coefficients, if postwar data are used in the estimation. Mulligan and Sala-i-Martin (2000) provided evidence that the money-demand interest rate elasticity differs, depending on the level of the interest rate. Clarida et al. (2000) found that there were different regimes in which monetary policy was conducted. Applying the time-varying parameter model, Kim and Nelson (2006) also showed that monetary policy rules have been different throughout the 1960s, the 1970s, the 1980s, and the 1990s. ${ }^{2}$ Furthermore, Wilson (1979) argued that the dynamics of the exchange rate differs depending on whether those changes in the policy were anticipated or not. The adjustments of misaligned currencies among countries, such as Plaza communiqué or Louvre Accord in the second half of the 1980s, must have also affected movements of the exchange rate (Eichengreen (2008)). Bacchetta and van Wincoop (2009) provided a theoretical model in which reduced form relationship between exchange rates and fundamentals can be varied by the changes in the expectation of parameters even though current structural parameters have not changed. Finally, Cheung and Chinn (2001) found from a survey of US foreign exchange traders that the importance, which foreign exchange traders attach to macroeconomic fundamentals in order to understand movements of exchange rates, shifts over time.

If the underlying parameters in the monetary model are varying over time, the economic environment is gradually changing and the importance rankings of macro variables in traders' mind change over time as previously mentioned, it might be too strong

\footnotetext{
2 Many of these studies focus on the US. However, the counterparts of the US could be subject to the same problems.
} 
to restrict coefficients in the monetary model. Furthermore, Bacchetta and van Wincoop (2011) demonstrate that if the underlying parameters in the model are constant but unknown, the relationship between exchange rates and macro fundamentals can vary over time. Hence, instead of imposing constant coefficients in the relation between exchange rates and macro fundamentals, we examine whether the exchange rates can be explained by the monetary model in which cointegration coefficients are varying.

Our motivation to use a time-varying econometric model is close to those in Wolff (1987) and Schinasi and Swamy (1989). Wolff (1987) employed the Kalman filtering approach to capture time-varying relation between the exchange rate and fundamentals under the assumptions of the random walk coefficients and known covariance matrices. However, nice asymptotic properties of the Kalman filtering approach can be obtained when observable variables (the exchange rate and fundamentals in Wolff (1987)) and state variables (time-varying coefficients in Wolff (1987)) are stationary (see Hamilton (1994)). Also, the results of the Kalman filtering approach could be sensitive to the assumption on the dynamic behavior of the state variables. Furthermore, the fact that fundamental variables are endogenous can make coefficient estimates have biases as admitted in Wolff (1987). Schinasi and Swamy (1989) applied a GLS approach to estimate time-varying coefficients under assumptions on structures of covariance matrices which are required for computations but are not justified theoretically. Facing these limits in previous studies, we employ the time-varying cointegration approach which considers explicitly the nonstationarity and endogeneity ${ }^{3}$ in the exchange rate and fundamental variables and puts no special priori assumptions on variances of error terms. Moreover, our approach enables us to obtain consistent estimates for the time-varying coefficients under the condition that

\footnotetext{
3 Our methodology, the canonical cointegrating regression model, enables us to obtain unbiased estimators without weak exogeneity assumption for fundamental variables.
} 
time-varying coefficients evolve smoothly.

Our study is also related with recent empirical studies such as Sarno et al. (2004) employing the nonlinear Markov-switching (MS) model and Kilian and Taylor (2003) employing the exponential smooth transition autoregressive (ESTAR) model in the sense that we have abandoned the simple linear approach. But, our approach is different in that we do not assume a fixed number of regimes or a specific nonlinear functional form $a$ priori. We estimate time-varying cointegration coefficients nonparametrically using series functions, which is proposed by Park and Hahn (1999) in order to avoid the misspecification problem due to parameter instability or a particular functional form $a$ priori. Also, our study is similar to Beckmann et al. (2009) in the sense that the relationship between the exchange rate and monetary fundamental is not permanently fixed, but different in the sense that we consider gradual and smooth changes in the relationship while Beckmann et al. (2009) considered discrete structural breaks in the relationship. After obtaining the time-varying cointegration coefficients, we further show that deviations from the time-varying long-run relation between the exchange rate and monetary fundamentals have predictive power for future changes in the exchange rates through in-sample, out-of-sample analyses and directional accuracy tests.

The remainder of the paper is organized as follows. Section 2 contains an assessment of the monetary model with constant and known coefficients examined in previous studies. In Section 3, we provide a brief theoretical discussion, our econometric methodology and statistical evidence for the monetary model with time-varying cointegration coefficients. ${ }^{4}$ Section 4 presents that deviations from the time-varying longrun relation between the exchange rate and monetary fundamentals have predictive power

\footnotetext{
${ }^{4}$ Although time-varying cointegration coefficients are not consistent at times with the standard monetary model in terms of their magnitudes and signs, we call the time-varying cointegration relationship between exchange rates and monetary fundaments as the monetary model with time-varying cointegration coefficients.
} 
for future changes in the exchange rates. Finally, concluding remarks are contained in Section 5.

\section{Monetary Model with Constant and Known Coefficients}

Consider a two-country model which can be described by the standard four equations:

$E_{t}\left(e_{t+1}\right)-e_{t}=\delta\left(i_{t}-i_{t}^{*}\right)+\pi_{t}$

$e_{t}=\beta\left(p_{t}-p_{t}^{*}\right)$

$m_{t}=p_{t}-\phi i_{t}+\gamma y_{t}+v_{t}$

$m_{t}^{*}=p_{t}^{*}-\phi i_{t}^{*}+\gamma y_{t}^{*}+v_{t}^{*}$

where $e_{t}, m_{t}, p_{t}$, and $y_{t}$, are the logarithms of the exchange rate, money supply, price level, and real income, respectively. $i_{t}$ is the level of the nominal interest rate. $\pi_{t}$ is the deviation from uncovered interest parity (UIP) or unobserved risk premium, while $v_{t}$ and $v_{t}^{*}$ denote unobserved velocity shocks. We assume that $\pi_{t}, v_{t}$ and $v_{t}^{*}$ follow stationary processes. $^{5} \gamma$ and $\phi$ denote the money-demand income elasticity and the money-demand interest rate semi-elasticity. Asterisks denote foreign variables.

Under the assumption that $\Delta\left(m_{t}-m_{t}^{*}\right) \sim$ i.i.d. $\left(0, \sigma_{m}^{2}\right)$ and $\Delta\left(y_{t}-y_{t}^{*}\right) \sim$ i.i.d. $\left(0, \sigma_{y}^{2}\right)$, it is straightforward to have the following expression for the exchange rate:

$e_{t}=\frac{\lambda_{1}}{1-\lambda_{2}}\left(m_{t}-m_{t}^{*}\right)-\frac{\lambda_{1} \gamma}{1-\lambda_{2}}\left(y_{t}-y_{t}^{*}\right)+\tilde{u}_{t}$

where $\lambda_{1}=\frac{\beta \delta}{\delta+\phi \beta}, \lambda_{2}=\frac{\phi \beta}{\delta+\phi \beta}, \tilde{u}_{t}=\lambda_{1}\left[u_{t}+E_{t}\left[\sum_{i=1}^{\infty} \lambda_{2}^{i} u_{t+i}\right]\right]$, and $u_{t}=\left(-\frac{\phi \pi_{t}}{\delta}+v_{t}^{*}-\right.$ $\left.v_{t}\right)$. We further assume that the underlying parameters $(\delta, \beta, \phi$, and $\gamma)$ are known to

\footnotetext{
${ }^{5}$ These unobserved processes are assumed to follow nonstationary processes in some recent studies such as Engel and West (2005) since they could not find cointegration evidence between the exchange rate and observable fundamentals. Using the time-varying cointegration approach, however, we find cointegration evidence for these variables as shown in the next section. As a result, we assume stationarity for these unobserved components.
} 
investors. Since $e_{t},\left(m_{t}-m_{t}^{*}\right)$, and $\left(y_{t}-y_{t}^{*}\right)$ are considered as I(1) variables and $\tilde{u}_{t}$ is an $\mathrm{I}(0)$ variable, Equation (5) implies that $e_{t},\left(m_{t}-m_{t}^{*}\right)$, and $\left(y_{t}-y_{t}^{*}\right)$ are cointegrated and the deviation from the cointegration relation has information about future exchange rate returns. Assuming that $\beta=\delta=\gamma=1$, previous studies (e.g. Mark (1995), Kilian (1999), etc.) tested this implication of the monetary model. Mark (1995) reported that the deviation from the cointegration relation has stronger predictive power for future changes in the exchange rate, as the forecast horizon increases. However, studies, like Kilian (1999) and Berkowitz and Giorgianni (2001), corrected the procedure in Mark (1995) and provided evidence against the exchange rate predictability based on the monetary model.

Although there could be reasons for the lack of supportive evidence towards the standard monetary model, this study focuses on the assumption that the cointegration vector between $e_{t},\left(m_{t}-m_{t}^{*}\right)$, and $\left(y_{t}-y_{t}^{*}\right)$ is fixed as $[1,-1,1]^{\prime}$ under the standard assumption of $\beta=\delta=\gamma=1$. The restriction means that the money-demand income elasticity $(\gamma)$ is constant and equal to the unity, the money-demand interest rate semielasticity $(\phi)$ is constant, both the PPP and UIP relations always hold, and the values of those parameters are known. According to previous studies in macroeconomics and international finance, however, these restrictions seem extremely strong. Probably, underlying parameters are varying over time or unknown. Furthermore, the interpretation of equations (1) - (4) can differ over time in investors' mind as demonstrated in Engel and West (2005). For example, Equation (1) may be interpreted as UIP or as monetary policy rule for non-US countries with the inclusion of exchange rates. $\delta$ is equal to 1 under UIP. In the latter interpretation, however, if monetary authorities set targets of the level of exchange rate and economic agents believe the monetary policy as a credible one, such a 
monetary policy and belief can result in negative $\delta .{ }^{6}$ Similarly, Equation (2) may be interpreted as PPP with $\beta=1$ or as reflecting the negative dynamic relation between the exchange rate and price after the overshooting of exchange rate in the Dornbusch (1976) model. Possibly due to these reasons, we also examine the plausibility of the monetary model with constant parameters other than $[1,-1,1]^{\prime}$. More specifically, we examine first whether deviations from the fundamental $\left(e_{t}-\left(m_{t}-m_{t}^{*}\right)+\left(y_{t}-y_{t}^{*}\right)\right)$ are stationary as assumed in the standard monetary model. When the unit root null hypothesis for this is not rejected, we will also search for the existence of any other constant cointegration relationships between $e_{t}$, $\left(m_{t}-m_{t}^{*}\right)$, and $\left(y_{t}-y_{t}^{*}\right)$ in this section.

\subsection{Data}

Empirical analyses in this paper require data for the exchange rates, money supply and real income, and all these data are obtained from International Financial Statistics (IFS) managed by the International Monetary Fund (IMF). ${ }^{7}$ The sample period is 1973 . II 2010. IV. The exchange rates include the Canadian dollars, Japanese Yens, Swiss francs, and UK pounds per the US dollar. While money plus quasi-money is used as the money supply for Switzerland and the UK, M2 serves as the money supply for Japan and Canada. ${ }^{8}$ For the US money supply, M2 is used. GDP volumes, which are normalized as 100 in 2005, are used for the measure of real income. Data for the money supply and real income are seasonally adjusted. All variables are constructed by the log transformation of these data, as in previous studies. Finally, the unit root null hypothesis cannot be rejected for exchange rates, relative money supply, and relative income at the $5 \%$ level with the

\footnotetext{
${ }^{6}$ In fact, a survey by Froot and Thaler (1990) reported that the average estimates for $\delta$ from 75 published studies is -0.88 . Chinn and Meredith (2004) proposed a model which augments a monetary reaction function to UIP relationship to understand the UIP anomalies.

${ }^{7}$ The version of IFS CD-ROM is April 2011.

${ }^{8}$ Empirical results are qualitatively similar even if M1 is used for Canada and Japan. However, money plus quasi-money is conceptually closer to M2 than M1.
} 
exception of the UK exchange rate. In addition, the unit root null can be rejected for all of these variables in their first differences at the $5 \%$ level. As a result, we assume that exchange rates, relative money supply, and relative income are I(1) variables as in the literature. $^{9}$

\subsection{Assessment of the Monetary Model with Constant Coefficients}

First, we investigate whether deviations from the fundamental $\left(z_{t}=e_{t}-\left(m_{t}-m_{t}^{*}\right)+\right.$ $\left.\left(y_{t}-y_{t}^{*}\right)\right)$ are stationary as assumed in the standard monetary model. That is, we conduct the $\mathrm{ADF}$ test for $z_{t}=e_{t}-\left(m_{t}-m_{t}^{*}\right)+\left(y_{t}-y_{t}^{*}\right)$. Hence, the following regression is run:

$z_{t}=c+\rho_{z} z_{t-1}+b_{1} \Delta z_{t-1}+b_{2} \Delta z_{t-2}+\cdots+b_{p} \Delta z_{t-p}+\varepsilon_{t}$

where the lag order is determined by the Akaike Information Criterion (AIC). As shown in Table 1 , the unit root null hypothesis for $z_{t}$ cannot be rejected in any country considered in this paper. These results suggest that the stable long-run relationship between the exchange rate and the macro fundamentals based on $[1,-1,1]^{\prime}$ cointegration vector, which is the restriction under the standard monetary model, does not exist.

Next, we examine whether any other constant cointegration relationship exists between $e_{t},\left(m_{t}-m_{t}^{*}\right)$, and $\left(y_{t}-y_{t}^{*}\right)$ rather than $[1,-1,1]^{\prime}$ cointegration vector. For this purpose, the test in Engle and Granger (1987) is conducted. For the Engle and Granger test, the cointegration coefficient is estimated by the OLS in the first step, and then the ADF test is conducted for the residuals from the first step. As presented in Table 2, the estimated cointegration coefficients are different from $[1,-1,1]^{\prime}$ in all countries considered. Furthermore, Engle and Granger's residual-based test results suggest that no cointegration relationship exists for any exchange rate studied in this paper at the $5 \%$ level.

\footnotetext{
9 The results of the ADF tests for these variables are provided in Appendix 1.
} 
That is, even after allowing for the constant cointegration relationship other than $[1,-1,1]^{\prime}$, the null hypothesis of no cointegration cannot be rejected at the $5 \%$ level in Table 2. In addition to the Engle and Granger test, the procedure proposed by Johansen (1988) and Johansen and Juselius (1990) is applied to detect the constant cointegrating relation between exchange rates and macro fundamentals. Based on the trace statistics and maximum eigenvalue statistics, the existence of the cointegration vectors is tested, and the number of cointegration vectors can be determined under this procedure. However, we cannot find a country where the null hypothesis of no cointegration is rejected by both statistics (trace statistics and maximum eigenvalue statistics) at the 5\% level, as shown in Table 3.

In summary, Table 1 demonstrates that $e_{t},\left(m_{t}-m_{t}^{*}\right)$, and $\left(y_{t}-y_{t}^{*}\right)$ are not cointegrated with $[1,-1,1]^{\prime}$. Furthermore, tables 2 and 3 together imply that no other constant cointegration relationship between $e_{t},\left(m_{t}-m_{t}^{*}\right)$, and $\left(y_{t}-y_{t}^{*}\right)$ exists. These results are consistent with previous studies such as Engel and West (2005), and suggest that the constant cointegration assumption is unrealistic. We view that the unrealistically strong assumption on the relationship between $e_{t},\left(m_{t}-m_{t}^{*}\right)$, and $\left(y_{t}-y_{t}^{*}\right)$ might be a reason for the poor performance of the standard monetary model in explaining movements of the exchange rate and for no existence of cointegration as well. Hence, we would like to examine the plausibility of the monetary model by allowing the cointegration relationship between $e_{t},\left(m_{t}-m_{t}^{*}\right)$, and $\left(y_{t}-y_{t}^{*}\right)$ to vary over time.

\section{Monetary Model with Time-varying Coefficients}

\subsection{Theoretical Discussion}

Based on the results in the previous section, which illustrate that the restriction of the constant cointegration relationship between $e_{t},\left(m_{t}-m_{t}^{*}\right)$, and $\left(y_{t}-y_{t}^{*}\right)$ is not 
supported by data, we consider a time-varying cointegration relationship between $e_{t}$, $\left(m_{t}-m_{t}^{*}\right)$, and $\left(y_{t}-y_{t}^{*}\right)$. Many studies have reported that underlying functions and relations (e.g. the PPP relation, money demand function, monetary policy rule, etc.) in the monetary model have parameter instabilities or regime changes. (Bierens and Martin (2010), Stock and Watson (1993), Mulligan and Sala-i-Martin (2000), Clarida et al. (2000), Kim and Nelson (2006), etc.) Also, misaligned currencies have been adjusted by negotiations between countries such as Plaza communiqué or Louvre Accord in the late 1980s (Eichengreen (2008)). The dynamics of the exchange rate may differ depending on whether policy changes are expected or not (Wilson (1979)). The ranking of important macro variables in foreign exchange traders' mind shifts over time (Cheung and Chinn (2001)). In addition, even if parameters are constant, Bacchetta and van Wincoop (2011) demonstrate that the cointegration coefficients are varying over time when these parameters are unknown and investors cannot separate fundamentals from unobservable components such as risk premium or velocity shocks. These findings suggest that it seems too strong to assume constant cointegration relationship between $e_{t},\left(m_{t}-m_{t}^{*}\right)$, and $\left(y_{t}-y_{t}^{*}\right)$. In order to incorporate the above results in various studies, we consider the following time-varying version of the standard model:

$$
\begin{aligned}
& E_{t}\left(e_{t+1}\right)-e_{t}=\delta_{t}\left(i_{t}-i_{t}^{*}\right)+\pi_{t} \\
& e_{t}=\beta_{t}\left(p_{t}-p_{t}^{*}\right) \\
& m_{t}=p_{t}-\phi_{t} i_{t}+\gamma_{t} y_{t}+v_{t} \\
& m_{t}^{*}=p_{t}^{*}-\phi_{t} i_{t}^{*}+\gamma_{t} y_{t}^{*}+v_{t}^{*}
\end{aligned}
$$

We allow $\delta, \beta, \phi$, and $\gamma$ to vary over time. Then, under the assumptions in the previous section, it is straightforward to derive the following time-varying regression equation:

$e_{t}=\alpha_{1 t}\left(m_{t}-m_{t}^{*}\right)+\alpha_{2 t}\left(y_{t}-y_{t}^{*}\right)+\tilde{u}_{t}$

where $\lambda_{1 t}=\frac{\beta_{t} \delta_{t}}{\delta_{t}+\phi_{t} \beta_{t}}, \lambda_{2 t}=\frac{\phi_{t} \beta_{t}}{\delta_{t}+\phi_{t} \beta_{t}}, \alpha_{1 t}=\lambda_{1 t}+\sum_{i=1}^{\infty} E_{t}\left[\left(\prod_{j=0}^{i-1} \lambda_{2 t+j}\right) \lambda_{1 t+i}\right]$ and 
$\alpha_{2 t}=-\gamma_{t} \lambda_{1 t}-\sum_{i=1}^{\infty} E_{t}\left[\left(\prod_{j=0}^{i-1} \lambda_{2 t+j}\right) \gamma_{t+i} \lambda_{1 t+i}\right]$

Instead of imposing the unrealistic restriction that $\alpha_{1 t}=1$ and $\alpha_{2 t}=-1$ or any other constant numbers for $\alpha_{1 t}$ and $\alpha_{2 t}$, we allow the cointegration coefficients to vary over time to reflect gradual changes in the cointegration relationship between $e_{t}$, $\left(m_{t}-m_{t}^{*}\right)$, and $\left(y_{t}-y_{t}^{*}\right)$. That is, Equation (11) states that although $e_{t},\left(m_{t}-m_{t}^{*}\right)$, and $\left(y_{t}-y_{t}^{*}\right)$ are individually $\mathrm{I}(1)$ variables, there exists a gradually changing cointegration vector which makes $e_{t}-\alpha_{1 t}\left(m_{t}-m_{t}^{*}\right)-\alpha_{2 t}\left(y_{t}-y_{t}^{*}\right)$ stationary. Cointegration coefficients evolve over time because of parameter instabilities in equations (1) - (4). Even the sign of $\alpha_{1 t}$ or $\alpha_{2 t}$ can change when foreign exchange traders shift exchange rate models from one to another as reported in Cheung and Chinn (2001). For example, when investors' view on the relation between interest differentials and exchange rates shifts gradually from UIP to monetary policy rule with exchange rates for non-US countries, $\delta_{t}$ changes its sign from positive to negative, which might result in a switch in the sign of $\alpha_{1 t}$ or $\alpha_{2 t}$ eventually. Also, when the main model to determine the relation between price differentials and exchange rates in investors' mind shifts smoothly from PPP to the Dornbusch model, the sign of $\beta_{t}$ changes, which might affect the sign of $\alpha_{1 t}$ or $\alpha_{2 t}$ in the end.

In addition, the scapegoat effect ${ }^{10}$ and Kalman filtering in Bacchetta and van Wincoop (2011) can generate time-varying cointegration relation even without the instability of underlying parameters. For the simplicity and the linkage with Bacchetta and van Wincoop (2011), suppose that $\delta=\beta=1$, other parameters are constant, the risk premia $\left(\pi_{t}\right)$ are zero, and the unobserved component $\left(u_{t}\right)$ follows an AR(1) process with

\footnotetext{
${ }^{10}$ When underlying parameters are unknown and investors cannot separate macro fundamentals from unobserved components, shocks from unobserved components are considered as changes in observed macro fundamentals by investors' optimally formed expectation. This channel can generate time-varying cointegration relation and is called as the scapegoat effect in Bacchetta and van Wincoop (2009, 2011).
} 
the AR(1) coefficient of $\rho$. Then, $e_{t}=f_{t}^{\prime}\left[\theta \mu+(1-\theta) E_{t}(\mu)\right]+\theta u_{t}$ where $f_{t}^{\prime}=\left[m_{t}-\right.$ $\left.m_{t}^{*} y_{t}-y_{t}^{*}\right], \mu^{\prime}=[1-\gamma]$, and $\theta=\frac{\lambda_{1}}{1-\rho \lambda_{2}}$. Although the Kalman filtering process makes $E_{t}(\mu)$ converge to the true parameter values, the scapegoat effect makes $E_{t}(\mu)$ fluctuate sharply. Numerical analyses in Bacchetta and van Wincoop (2009, 2011) show that $E_{t}(\mu)$ can fluctuate at higher frequency even though parameters are constant or very slowly changing. Furthermore, the sign of $E_{t}(\mu)$ can switch due to the scapegoat effect.

We think that both parameter instabilities and the scapegoat effect can be a reason for the time-varying cointegration coefficients. However, the pattern of estimated cointegration parameters may provide a clue about the main reason for the time-varying cointegration relation. While changes in structural parameters may result in a gradual change in the cointegration coefficients, the scapegoat effect can cause the cointegration parameters to have sharper fluctuations as shown in the numerical analyses in Bacchetta and van Wincoop (2009, 2011). Hence, if estimated cointegration parameters have long swings, then gradual changes in structural parameters may be a reason for unstable cointegration relation. Alternatively, if the estimated parameters show some sharp fluctuations similarly to the numerical exercise in Bacchetta and van Wincoop (2009, 2011), then the scapegoat effect may be a dominant reason for the time-varying cointegration.

\subsection{Econometric Methodology}

Given the evidence of the rejection for the constant cointegration relation, we apply the methodology proposed by Park and Hahn (1999) to estimate the time-varying cointegration parameters. Let $\alpha_{1 t}=\alpha_{1}\left(\frac{t}{T}\right)$ and $\alpha_{2 t}=\alpha_{2}\left(\frac{t}{T}\right)$ so that $\alpha_{1}$ and $\alpha_{2}$ are smooth functions defined on $[0,1]$, while $T$ is the sample size. The only assumption for $\alpha_{1}$ and $\alpha_{2}$ is that they are sufficiently smooth to be approximated by a series of 
polynomials and/or trigonometric functions. Thus, $\alpha_{1}$ and $\alpha_{2}$ can be approximated by $\alpha_{1 \kappa_{1}}=\sum_{i=1}^{\kappa_{1}} \theta_{i}^{m} \varphi_{i}^{m}$ and $\alpha_{2 \kappa_{2}}=\sum_{i=1}^{\kappa_{2}} \theta_{i}^{y} \varphi_{i}^{y}$, respectively for some finite numbers $\kappa_{1}$ and $\kappa_{2}$. Then, the above econometric model can be expressed as follows:

$$
\begin{aligned}
e_{t} & =\alpha_{0}+\alpha_{1 t}\left(m_{t}-m_{t}^{*}\right)+\alpha_{2 t}\left(y_{t}-y_{t}^{*}\right)+u_{t} \\
& =\alpha_{0}+\alpha_{1}\left(\frac{t}{T}\right)\left(m_{t}-m_{t}^{*}\right)+\alpha_{2}\left(\frac{t}{T}\right)\left(y_{t}-y_{t}^{*}\right)+u_{t} \\
& =\alpha_{0}+\left[\sum_{i=1}^{\kappa_{1}} \theta_{i}^{m} \varphi_{i}^{m}\left(\frac{t}{T}\right)\right]\left(m_{t}-m_{t}^{*}\right)+\left[\sum_{i=1}^{\kappa_{2}} \theta_{i}^{y} \varphi_{i}^{y}\left(\frac{t}{T}\right)\right]\left(y_{t}-y_{t}^{*}\right)+u_{\kappa t} \\
& =\alpha_{0}+\chi_{\kappa_{1} t}^{m \prime} a_{\kappa_{1}}^{m}+\chi_{\kappa_{2} t}^{y \prime} a_{\kappa_{2}}^{y}+u_{\kappa t}
\end{aligned}
$$

where $\chi_{\kappa_{1} t}^{m}=\left[\varphi_{1}^{m}\left(\frac{t}{T}\right), \ldots, \varphi_{\kappa_{1}}^{m}\left(\frac{t}{T}\right)\right]^{\prime}\left(m_{t}-m_{t}^{*}\right), \chi_{\kappa_{2} t}^{y}=\left[\varphi_{1}^{y}\left(\frac{t}{T}\right), \ldots, \varphi_{\kappa_{2}}^{y}\left(\frac{t}{T}\right)\right]^{\prime}\left(y_{t}-y_{t}^{*}\right)$,

$$
\begin{aligned}
& a_{\kappa_{1}}^{m}=\left[\theta_{1}^{m}, \ldots, \theta_{\kappa_{1}}^{m}\right]^{\prime}, a_{\kappa_{2}}^{y}=\left[\theta_{1}^{y}, \ldots, \theta_{\kappa_{2}}^{y}\right]^{\prime}, \text { and } u_{\kappa t}=u_{t}+\left[\alpha_{1}\left(\frac{t}{T}\right)-\alpha_{1 \kappa_{1}}\left(\frac{t}{T}\right)\right]\left(m_{t}-m_{t}^{*}\right)+ \\
& {\left[\alpha_{2}\left(\frac{t}{T}\right)-\alpha_{2 \kappa_{2}}\left(\frac{t}{T}\right)\right]\left(y_{t}-y_{t}^{*}\right) .}
\end{aligned}
$$

Since $e_{t},\left(m_{t}-m_{t}^{*}\right)$, and $\left(y_{t}-y_{t}^{*}\right)$ are nonstationary, we apply the canonical cointegrating regression (CCR) in Park (1992) to obtain desirable asymptotic results. Then, Equation (12) becomes

$e_{t}^{\dagger}=\alpha_{0}+\chi_{\kappa_{1} t}^{m \dagger \prime} a_{\kappa_{1}}^{m}+\chi_{\kappa_{2} t}^{y \dagger \prime} a_{\kappa_{2}}^{y}+u_{\kappa t}^{\dagger}$

where $\chi_{\kappa_{1} t}^{m \dagger}=\left[\varphi_{1}^{m}\left(\frac{t}{T}\right), \ldots, \varphi_{\kappa_{1}}^{m}\left(\frac{t}{T}\right)\right]^{\prime}\left(m_{t}-m_{t}^{*}\right)^{\dagger}, \quad \chi_{\kappa_{2} t}^{y \dagger}=\left[\varphi_{1}^{y}\left(\frac{t}{T}\right), \ldots, \varphi_{\kappa_{2}}^{y}\left(\frac{t}{T}\right)\right]^{\prime}\left(y_{t}-\right.$ $\left.y_{t}^{*}\right)^{\dagger}$, and superscript $\dagger$ denotes CCR transformed variables. Once the LS estimators for $a_{\kappa_{1}}^{m}$ and $a_{\kappa_{2}}^{y}$ are obtained, then $\alpha_{1}$ and $\alpha_{2}$ can be approximated by $\widehat{\alpha_{1 \kappa_{1}}}=\sum_{i=1}^{\kappa_{1}} \widehat{\theta_{l}^{m}} \varphi_{i}^{m}$ and $\widehat{\alpha_{2 \kappa_{2}}}=\sum_{i=1}^{\kappa_{2}} \widehat{\theta_{l}^{y}} \varphi_{i}^{y}$, respectively. We employ Fourier Flexible Form (FFF) series functions, which include polynomials and trigonometric functions, to approximate $\alpha_{1}$ and $\alpha_{2}{ }^{11}$

\footnotetext{
${ }^{11}$ Regarding how to choose $\kappa_{1}$ and $\kappa_{2}$, econometric theories do not provide any guide yet. However, the misspecification tests in Park and Hahn (1999) are not sensitive to the choice of $\kappa_{1}$ and $\kappa_{2}$.
} 


\subsection{Assessment of the Monetary Model with Time-Varying Coefficients}

To find out the adequacy of the time-varying cointegration relationship between $e_{t}$, $\left(m_{t}-m_{t}^{*}\right)$, and $\left(y_{t}-y_{t}^{*}\right)$, model specification tests proposed by Park and Hahn (1999) are conducted. Two test statistics, employed to test the null of constant cointegration parameters against the alternative of time-varying cointegration parameters, are $\tau_{1}^{*}=$ $\frac{R S S_{F C^{-}-R S S_{F C}^{S}}}{\widehat{\omega}_{T k}^{2 *}}$ and $\tau_{2}^{*}=\frac{\sum_{t=1}^{T}\left(\sum_{i=1}^{t} \widehat{u}_{i}^{*}\right)^{2}}{T^{2} \widehat{\omega}_{T k}^{2 *}} . R S S_{F C}$ is the sum of squared residuals from the restricted cointegration vector $[1,-1,1]^{\prime}$ or from the CCR transformed regression with constant coefficients. We examine both cases in Table 4. $R S S_{F C}^{S}$ is the sum of squared residuals from the CCR transformed regression augmented with superfluous regressors. We include time polynomials $t, t^{2}, t^{3}, t^{4}$, and $t^{5}$ as superfluous regressors. $\widehat{\omega}_{T k}^{2 *}$ is the long-run variance estimate of transformed errors $\hat{u}_{\kappa t}^{\dagger}$ in Equation (13) and $\hat{u}_{i}^{*}$ is the fitted residuals of the transformed regression with constant coefficients. In order to estimate $\widehat{\omega}_{T k}^{2 *}$, the Bartlett kernel is used with the lag truncation value selected by the method in Andrews (1991). Test results are presented in the first three rows of Table 4. The null hypothesis that $[1,-1,1]^{\prime}$ is the cointegration vector between $e_{t},\left(m_{t}-m_{t}^{*}\right)$, and $\left(y_{t}-y_{t}^{*}\right)$ or that another constant cointegration relationship exists between these variables is rejected unanimously in all cases considered. We also test the null of constant cointegration parameters against the alternative of time-varying cointegration employing the Lagrange ratio test developed by Bierens and Martin (2010). The fourth row in Table 4 shows that the null of constant cointegration is strongly rejected again. Thus, null hypotheses of constant cointegration are greatly rejected in favor of the time-varying cointegration relationship between these variables in all countries, regardless of test methods considered. ${ }^{12}$

\footnotetext{
${ }^{12}$ The results shown in the fourth row of Table 4 are the test statistics when the number of Chebyshev
} 
Further, we investigate whether the rejection of the constant cointegration relationship is due to no cointegration relationship at all between these variables or due to the time-varying cointegration relationship between these variables. For this purpose, we employ $\tau^{*}=\frac{R S S_{T V C^{-R S S}} S}{\widehat{\omega}_{T k}^{2 *}}$ where $R S S_{T V C}$ is the sum of squared residuals from the CCR transformed regression with time-varying coefficients and $R S S_{T V C}^{S}$ is the sum of squared residuals from the time-varying-coefficient CCR transformed regression augmented with superfluous regressors. The null hypothesis is that there exists a time-varying cointegration relationship between $e_{t}$, $\left(m_{t}-m_{t}^{*}\right)$, and $\left(y_{t}-y_{t}^{*}\right)$, while the alternative hypothesis is that there is no cointegration at all. Hence, $\tau^{*}$ diverges if there is no time-varying cointegrating relation. As shown in the last row of Table $4, \tau^{*}$ is much lower than the $5 \%$ critical value (11.07) for all countries considered in this paper. Therefore, we conclude that our results in Table 4 refute the restriction imposed in the standard monetary model in favor of the monetary model with time-varying coefficients.

Since the monetary model with time-varying coefficients is supported by data, we estimate the time-varying cointegration parameters utilizing the Park and Hahn (1999) method. Figures 1 and 2 show estimated $\alpha_{1 t}$ (the time-varying coefficient for $\left(m_{t}-\right.$ $\left.m_{t}^{*}\right)$ ) and $\alpha_{2 t}$ (the time-varying coefficient for $\left(y_{t}-y_{t}^{*}\right)$ ) in Equation (11), respectively along with 95\% confidence bands. In all cases, the estimated cointegration parameters are far from being constant. Moreover, some estimated coefficients ( $\hat{\alpha}_{1 t}$ for the UK and $\hat{\alpha}_{2 t}$ for Canada, Japan, and Switzerland) show smooth U-shaped or hump-shaped patterns, which might reflect gradual shifts in structural parameters. However, others show some fluctuations which might be related with the changes in expectations of parameters reflecting the scapegoat effect. According to the pattern of estimated cointegration coefficients, both (gradual shifts in structural parameters and the scapegoat effect) seem to 
be reasons for the time-varying cointegration relation between exchange rates and macro fundamentals.

When time-varying coefficients are estimated with no restrictions on their movements or direction, some estimated coefficients in figures 1 and 2 are not consistent with the standard monetary model. For example, positive coefficients for $\left(m_{t}-m_{t}^{*}\right)$ and positive coefficients for $\left(y_{t}-y_{t}^{*}\right)$ are observed for Japan and Switzerland at times. Also, negative coefficients for $\left(m_{t}-m_{t}^{*}\right)$ and positive coefficients for $\left(y_{t}-y_{t}^{*}\right)$ are found at times in Canada. These results imply that various models might be considered by traders, which could yield seemingly odd and switching signs from the viewpoint of the standard monetary model.

Possible models and interpretations for such results are as follows: Expansionary monetary policy in the Mundell-Fleming model results in the depreciation of the exchange rate and increase in income, which is consistent with positive coefficients for $\left(m_{t}-m_{t}^{*}\right)$ and positive coefficients for $\left(y_{t}-y_{t}^{*}\right)$. In addition, when monetary authorities manage interest rates to smooth their movements and to avoid drastic changes in exchange rates, the estimates of $\delta$ in $E_{t}\left(e_{t+1}\right)-e_{t}=\delta\left(i_{t}-i_{t}^{*}\right)+\pi_{t}$ could be negative as argued in McCallum (1994). The combination of this relation between the exchange rate and interest rate differentials with the typical small open economy model as in McCallum (1994) can generate negative coefficients for $\left(m_{t}-m_{t}^{*}\right)$ and positive coefficients for $\left(y_{t}-y_{t}^{*}\right)$ with given expectations for the exchange rate and price, reflecting the monetary authorities behavior. If negative $\delta$ in $E_{t}\left(e_{t+1}\right)-e_{t}=\delta\left(i_{t}-i_{t}^{*}\right)+\pi_{t}$ is combined with PPP deviations (e.g. the Harrod-Balassa-Samuelson effect, long-run adjustments of exchange rates and prices after the overshooting in Dorbusch (1976), etc.) which could make negative $\beta$ in $e_{t}=\beta\left(p_{t}-p_{t}^{*}\right)$, then the model, described by equations (1) - (4), could also yield negative coefficients for $\left(m_{t}-m_{t}^{*}\right)$ and positive coefficients for $\left(y_{t}-y_{t}^{*}\right)$. 
Finally, when investors are not able to distinguish macro fundamentals from unobserved shocks, seemingly odd coefficients could also be possible, as demonstrated in numerical analyses in Bacchetta and van Wincoop (2009, 2011) (e.g. the scapegoat effect).

Figure 3 indicates the residuals from the time-varying cointegration regression along with the residuals from the cointegration vector of $[1,-1,1]^{\prime}$. The residuals from the time-varying cointegration regression seem much more stable and stationary than those from the cointegration vector of $[1,-1,1]^{\prime}$, which is consistent with the results in Table 4 .

\section{Monetary Model with Time-Varying Coefficients and the Predictability of Exchange Rate}

\subsection{In-Sample Analysis of Exchange Rate Predictability}

Section 3 demonstrates that the cointegration relation between $e_{t},\left(m_{t}-m_{t}^{*}\right)$, and $\left(y_{t}-y_{t}^{*}\right)$ varies over time, which implies that the long-run equilibrium relation is varying over time. The time-varying long-run equilibrium relation might be due to unstable parameters in the PPP relation or in the money demand function, changing monetary policies among countries, adjustments of misaligned exchange rates by negotiations among countries, gradual shifts in traders' view, and the scapegoat effect. Then, the model based on monetary fundamentals could imply that current deviations from the (gradually timevarying) long-run equilibrium value of the exchange rate are expected to be useful in predicting future changes of the exchange rate. We check this possibility in Section 4. Thus, we run the following predictive regressions for various horizons:

$e_{t+k}-e_{t}=a_{k}+\beta_{k} z_{t}^{T V C}+w_{t+k, t}$

where $z_{t}^{T V C}=e_{t}-\alpha_{1 t}\left(m_{t}-m_{t}^{*}\right)-\alpha_{2 t}\left(y_{t}-y_{t}^{*}\right)$. As the exchange rate is expected to move toward the long-run equilibrium over time, $\beta_{k}$ should be negative. Considering possible heteroskedasticity and serial correlations in $w_{t+k, t}$, we employ the Hodrick 
standard errors in conducting T-tests on $\beta_{k} \cdot{ }^{13}$ We compare the performance of the timevarying coefficient model with that of the constant coefficient model by replacing $z_{t}^{T V C}$ with $z_{t}=e_{t}-\alpha_{1}\left(m_{t}-m_{t}^{*}\right)+\alpha_{2}\left(y_{t}-y_{t}^{*}\right)$.

Table 5 reports the estimated slope coefficient $\left(\beta_{k}\right)$ along with its t-test statistics for various horizons with the full sample. All estimated coefficients from the time-varying cointegration model in Table 5 are negative and significantly different from zero, which is consistent with the model based on monetary fundamentals. That is, when the current exchange rate is higher than the fundamentals, the exchange rate tends to fall. Unlike the time-varying cointegration model, however, insignificant slope coefficients are found for many cases under the constant coefficient regression model. ${ }^{14}$

Since the slope coefficient of $z_{t}^{T V C}$ becomes larger than the unity from the fourquarter horizon for Canada, the eight-quarter horizon for Japan and Switzerland, and the 12-quarter horizon for the UK, exchange rates are likely to move as much as cointegrating errors within these periods of time in the countries. These speeds of adjustment are consistent with the persistence of $z_{t}^{T V C}$, measured by $\operatorname{AR}(1)$ coefficients. $\operatorname{AR}(1)$ coefficients for $z_{t}^{T V C}$ are $0.68,0.73,0.74$, and 0.82 for Canada, Japan, Switzerland, and the UK, respectively. Hence, it takes longer time for the exchange rate to adjust to the long-run equilibrium level as $z_{t}^{T V C}$ becomes more persistent. ${ }^{15}$

\subsection{Out-of-Sample Analysis of Exchange Rate Predictability}

\footnotetext{
13 Ang and Bekaert (2007) demonstrate that the Hodrick standard errors perform better than the Newey-West standard errors in the long-horizon predictive regression.

${ }^{14}$ Critical values for time-invariant model are actually larger than those for time-varying model in absolute values since the exchange rates and fundamentals are not cointegrated under the assumption of constant relationship. According to Berkowitz and Giorgianni (2001), both the estimate of $\beta_{\mathrm{k}}$ and the distribution of the t-statistics are skewed to the left when the error correction terms are not stationary.

${ }^{15}$ Further investigation for the different AR(1) coefficients for $z_{t}^{T V C}$ are beyond the purpose of this study. The differences may result from different structural parameters, legal and cultural difference, differences of monetary authority's preference, etc.
} 
In order to see whether the presence of strong in-sample prediction performance leads to significant out-of-sample prediction performance, we compare the out-of-sample performances of the predictive regressions that employ $z_{t}^{T V C}=e_{t}-\alpha_{1 t}\left(m_{t}-m_{t}^{*}\right)-$ $\alpha_{2 t}\left(y_{t}-y_{t}^{*}\right)$ relative to those of the random walk without drift model as well as those from the predictive regression with $z_{t}=e_{t}-\alpha_{1}\left(m_{t}-m_{t}^{*}\right)+\alpha_{2}\left(y_{t}-y_{t}^{*}\right)$. The random walk without drift model has been the benchmark to evaluate the out-of-sample performance of exchange rate models in many studies since Messe and Rogoff (1983). The out-of-sample analysis with $z_{t}^{T V C}$ is conducted as follows. First, the cointegrating errors $\left\{z_{t}^{T V C}\right\}_{t=1}^{t_{0}}$ are constructed based on time-varying cointegrating coefficients estimated in regression equation (11) with the exchange rate and fundamental data up to time $t_{0}$. Then, we run regression (14) of $\left\{e_{t+k}-e_{t}\right\}_{t=1}^{t_{0}-k}$ on $\left\{z_{t}^{T V C}\right\}_{t=1}^{t_{0}-k}$ to estimate $a_{k}$ and $\beta_{k}$. With $z_{t_{0}}^{T V C}$ and the estimates of $a_{k}$ and $\beta_{k}$, we make a forecast for $\widehat{e_{t_{0}+k}}-e_{t_{0}}$. Next, we repeat these steps to predict $\widehat{e_{t_{0}+k+1}}-e_{t_{0}+1}$, after adding the observations of the exchange rate and fundamental data at $t_{0}+1$ and removing the oldest observations to keep the window size fixed. The initial forecasting point starts from the second quarter of 1991, which is the middle point of our sample.

We compare the out-of-sample performance of the predictive regression with $z_{t}^{T V C}$ against that of a random walk model or that of the predictive regression with $z_{t}$ by employing the Clark and West (2007) test statistic. The null hypothesis is that two competing forecasting models have an equal mean squared prediction error. Table 6 reports the test results. We construct the Clark-West test statistic so that it has a significantly positive sign if the regression model with $z_{t}^{T V C}$ as a regressor exhibits superior predictive power in relation to the random walk model or to the time-invariant model.

The upper panel of Table 6 shows that the Clark-West statistics against the random 
walk model are significant at the $10 \%$ level or above at the eight-quarter horizon for Canada, at the one-quarter horizon for Japan, at the four-quarter through the eight-quarter horizons for Switzerland, and the 16-quarter horizon for the UK. The timings of the significant Clark-West statistics generally coincide with the persistence of $z_{t}^{T V C}$ in Figure 3 with the exception of Canada, which suggests that the timing of the significant ClarkWest statistics is related with the speed of adjustment toward the long-run equilibrium. While the slope coefficients of $z_{t}^{T V C}$ in the predictive regression are significant for all horizons in all countries in the in-sample analysis, the significant predictive power is not unanimous but appears to depend on horizons (or the speed of adjustment) in the out-ofsample analysis. This deterioration of the performance seems to be related with the loss of power resulting from shorter sample size for the estimation in the out-of-sample analysis, as emphasized by Inoue and Kilian (2004) and Bacchetta et al. (2010).

The lower panel of Table 6 compares the out-of-sample performance of the timevarying cointegration model and that of the time-invariant model. As shown in the lower panel of Table 6, the time-varying cointegration model significantly outperforms the timeinvariant model in most cases, even if the out-of-sample performance from both models is measured by rolling regressions with the same sample size. The reason for this result is that the estimation error from the time-varying cointegration model includes the small sample errors, whereas the estimation error from the time-invariant model includes not only the small sample errors but also misspecification errors under the unstable cointegration relation between the exchange rate and fundamentals. In order to assess this reasoning further, we simulate 1,000 series of the exchange rates using the estimated timevarying cointegration parameters and estimated time-varying cointegration residuals. ${ }^{16}$ Then, we compare the mean squared forecast errors from the time-varying cointegration

${ }^{16}$ A detailed description of the simulation is provided in Appendix 2. 
model and the time-invariant model. Table 7 presents the ratio of mean squared forecast errors, defined as the mean squared forecast errors from the time-varying cointegration model divided by that from the time-invariant model, and shows that this ratio is below one at all horizons except for the one-quarter horizon. Moreover, the ratio tends to decrease as the horizon increases. These results suggest the importance of correct and flexible specification when cointegration coefficients are varying over time. Simple linear rolling regression has misspecification problem and results in worse performance in forecasting changes in the exchange rate than the time-varying rolling regression.

\subsection{Directional Accuracy Test}

In addition to the standard evaluation of forecast performance in previous sub-sections, we consider the directional accuracy test in Cheung et al. (2005) to examine whether the model based on monetary fundamentals with a time-varying cointegration relation has good ability in predicting the direction of changes in the exchange rates. The result of the directional accuracy test may be utilized in forming an appropriate trading strategy to improve economic profits, as argued in Cheung et al. (2005). Hence, we compute the proportion of forecasts that correctly predict directional changes in the exchange rate based on the monetary model with time-varying cointegration coefficients. This proportion is reported in Table 8 along with the p-values for the hypothesis that the reported proportion is significantly larger or lower than $0.5{ }^{17}$ As shown in Table 8 , the probability of correct signs under the monetary model with a time-varying cointegration relation is well above 0.5 for at least one case in all countries considered. More specifically, the test statistics are significant at the eight-quarter through the 12-quarter horizons for Canada, at the fourquarter horizon for Japan, at the eight-quarter through the 16-quarter horizons for

\footnotetext{
${ }^{17}$ Under the random walk model without drift, the probability that the exchange rate will rise is equal to the probability that the exchange rate will fall.
} 
Switzerland, and at the eight-quarter and the 16-quarter horizons in the UK. These results suggest that the time-varying monetary model has notable ability in predicting the direction of changes in the exchange rates at intermediate horizons. Interestingly, the timings that significant test statistics are obtained from the directional accuracy tests roughly coincide with those from the out-of-sample analyses in the previous sub-section.

\section{Conclusion}

Many studies have pointed out that the underlying relations and functions for the monetary model (e.g. the PPP relation, the money demand function, monetary policy rule, economic models in traders' mind, etc.) have undergone parameter instabilities, which imply a timevarying cointegration relation between the exchange rate and monetary fundamentals. Also, unknown parameters and inability to distinguish fundamentals from unobserved components can cause the cointegration relation between the exchange rate and fundamentals to fluctuate over time. Hence, the failure to consider this time-varying longrun relationship might have resulted in poor forecast performance of the standard monetary model. Consistent with this observation, we provide statistical evidence for the monetary model with time-varying cointegration parameters. Furthermore, we demonstrate that deviations between the exchange rate and the monetary fundamentals from the model with time-varying cointegration coefficients have strong predictive power for future changes in the exchange rates through in-sample analysis, out-of-sample analysis, and directional accuracy tests. 


\section{References}

Andrews, D.K., 1991. Heteroskedasticity and Autocorrelation Consistent Covariance Matrix Estimation. Econometrica 59, 817-858.

Ang, A., Bekaert, G., 2007. Stock return predictability: Is it there? Review of Financial Studies 20, 651-707.

Bacchetta, P., van Wincoop, E., 2009. On the Unstable Relationship between Exchange Rates and Macroeconomic Fundamentals. NBER Working Paper 15008.

Bacchetta, P., van Wincoop, E., 2011. On the Unstable Relationship between Exchange Rates and Macroeconomic Fundamentals. Working Paper, University of Virginia.

Bacchetta, P., van Wincoop, E., Beutler, T., 2010. Can Parameter Instability Explain the Meese-Rogoff Puzzle? NBER International Seminar on Macroeconomics 2009, 125-173.

Beckmann, J., Belk, A.H., Kühl, M., 2011. The dollar-euro exchange Rate and macroeconomic fundamentals: a time-varying coefficient approach. Review of World Economics 147, 11-40.

Berkowitz, J., Giorgianni L., 2001. Long Horizon Exchange Rate Predictability? Review of Economics and Statistics 83, 81-91.

Bierens, H., Martins, L., 2010. Time-Varying Cointegration. Econometric Theory 26, 1453-1490.

Cheung, Y., Chinn, M.D., 2001. Currency Traders and Exchange Rate Dynamics: A Survey of the US Market. Journal of International Money and Finance 20, 439-471.

Cheung, Y., Chinn M.D., Pascual, A.G., 2005. Empirical Exchange Rate Models of the Nineties: Are Any Fit to Survive. Journal of International Money and Finance 24, 11501175.

Chinn, M.D., Meese, R.A., 1995. Banking on Currency Forecasts: How Predictable is Change in Money? Journal of International Economics 38, 161-178.

Chinn, M.D., Meredith, G., 2004. Monetary Policy and Long-Horizon Uncovered Interest Parity. IMF Staff Papers 51, 409-430.

Clarida, R., Gal'ı, J., Gertler, M., 2000. Monetary Policy Rules and Macroeconomic Stability: Evidence and Some Theory. Quarterly Journal of Economics 115, 147-180.

Clark, T.E., West, K.D., 2007. Approximately normal tests for equal predictive accuracy in nested models. Journal of Econometrics 138, 291-311.

Dornbusch R., 1976. Expectations and Exchange Rate Dynamics. Journal of Political Economy 84, 1161-1176.

Eichengreen, B., 2008. Globalizing capital: a history of the international monetary system, 
$2^{\text {nd }}$ ed. Princeton University Press, 134-149.

Engel, C., West, K.D., 2005. Exchange Rates and Fudnamentals. Journal of Political Economy 113, 485-517.

Froot, K.A., Thaler, R.H., 1990. Anomalies: Foreign Exchange. The Journal of Economic Perspectives 4, 179-192.

Fujiwara, I., Koga, M., 2004. A Statistical Forecasting Method for Inflation Forecasting: Hitting Every Vector Autoregression and Forecasting under Model Uncertainty. Monetary and Economic Studies 22, 123-142.

Hamilton, J.D., 1994. Time Series Analysis. Princeton Press.

Hodrick, R.J., 1992. Dividend Yields and Expected Stock Returns: Alternative procedures for inference and measurement. The Review of Financial Studies 5, 357-386.

Inoue, A., Kilian, L., 2004. In-sample or out-of-sample tests of predictability: Which one should we use? Econometric Reviews 23, 371-402.

Johansen, S., 1988. Statistical Analysis of Cointegrating Vectors. Journal of Economic Dynamics and Control 12, 231-254.

Johansen, S., Juselius, K., 1990. Maximum Likelihood Estimation and Inference on Cointegration - With Applications to the Demand for money. Oxford Bulletin of Economics and Statistics 62, 169-210.

Kilian, L., 1999. Exchange Rates and Monetary Fundamentals: What Do We Learn from Long-Horizon Regressions? Journal of Applied Econometrics 14, 491-510.

Kilian, L., Taylor, M., 2003. Why Is It So Difficult to Beat the Random Walk Forecast of Exchange Rates? Journal of International Economics 60, 85-107.

Kim, C., Nelson, C., 2006. Estimation of a Forward-Looking Monetary Policy Rule:

A Time-Varying Parameter Model using Ex-Post Data. Journal of Monetary Economics 53, 1949-1966.

MacKinnon, J.G., 1996. Numerical Distribution Functions for Unit Root and Cointegration Tests. Journal of Applied Econometrics 11, 601-618.

MacKinnon, J.G., Haug, A.A., Michelis, L., 1999. Numerical Distribution Functions of Likelihood Ratio Tests for Cointegration. Journal of Applied Econometrics 14, 563-577.

Mark, N.C., 1995. Exchange rates and fundamentals: evidence on long-horizon predictability. The American Economic Review 85, 201-218.

McCallum, B.T., 1994. A reconsideration of the uncovered interest parity relationship. Journal of Monetary Economics 33, 105-132.

Meese, R.A., Rogoff, K., 1983. Empirical Exchange Rate Models of the Seventies: Do 
They Fit Out of Sample? Journal of International Economics 14, 3-24.

Mulligan, C.B., Sala-i-Martin, X., 2000. Extensive Margins and the Demand for Money at Low. Interest Rates. Journal of Political Economy 108, 961-91.

Park, J.Y., 1992. Canonical cointegration regressions. Econometrica 60, 119-143.

Park, J.Y., Hahn, S.B., 1999. Cointegrating regression with time varying coefficients. Econometric Theory 15, 664-703.

Phillips, P.C.B., Ouliaris, S., 1990. Asymptotic Properties of Residual Based Tests for Cointegration. Econometrica 58, 165-193.

Rogoff, K., 2009. Exchange rates in the modern floating era: what do we really know? Review of World Economics 145, 1-12.

Sarno, L., Valente, G., Wohar, M., 2004. Monetary Fundamentals and Exchange Rate Dynamics Under Different Nominal Regimes. Economic Inquiry 42, 179-193.

Schinasi, G.J., Swamy P.A.V.B., 1989. The Out-of-sample Forecasting Performance of Exchange Rate Models When Coefficients are Allowed to Change. Journal of International Money and Finance 8, 375-390.

Shin, Y., 1994. A residual-based test of the null of cointegration against the alternative of no cointegration. Econometric Theory 10, 91-115.

Stock, J., Watson, M., 1993. A Simple Estimator of Cointegrating Vectors in Higher Order Integrated Systems. Econometrica 61, 783-820.

Wilson, C.A., 1979. Anticipated Shocks and Exchange Rate Dynamics. Journal of Political Economy 87, 639-647.

Wolff, C.C., 1987. Time-Varying Parameters and the Out-of-sample Forecasting Performance of Structural Exchange Rate Models. Journal of Business and Economic Statistics 5, 87-97. 
Appendix 1. Augmented Dickey-Fuller Test for Variables in the Monetary Model

\begin{tabular}{|c|c|c|c|c|c|}
\hline \multicolumn{2}{|c|}{ Variables } & Canada & Japan & Switzerland & UK \\
\hline \multirow{2}{*}{$e_{t}$} & level & -1.717 & -1.141 & -1.641 & -3.151 \\
& & $(0.420)$ & $(0.699)$ & $(0.459)$ & $(0.025)$ \\
\cline { 2 - 6 } & First difference & -9.078 & -5.803 & -6.532 & -9.709 \\
& & $(0.000)$ & $(0.000)$ & $(0.000)$ & $(0.000)$ \\
\hline$\left(m_{t}-m_{t}^{*}\right)$ & level & -1.860 & -0.911 & -2.612 & -0.834 \\
& & $(0.351)$ & $(0.782)$ & $(0.093)$ & $(0.806)$ \\
\cline { 2 - 6 } & First difference & -3.831 & -2.919 & -11.595 & -12.072 \\
& & $(0.003)$ & $(0.046)$ & $(0.000)$ & $(0.000)$ \\
\hline$\left(y_{t}-y_{t}^{*}\right)$ & level & -1.312 & -0.134 & -1.160 & -1.774 \\
& & $(0.623)$ & $(0.943)$ & $(0.691)$ & $(0.392)$ \\
\cline { 2 - 6 } & First difference & -11.844 & -5.777 & -3.139 & -12.953 \\
& & $(0.000)$ & $(0.000)$ & $(0.026)$ & $(0.000)$ \\
\hline
\end{tabular}

Note: Numbers in parentheses are MacKinnon (1996) one-sided p-values for the ADF test statistics. Each lag length is determined by the Akaike Information criterion (AIC). 


\section{Appendix 2. Algorithm for Comparison of Mean Squared Forecast Errors in Table 7}

1. Estimate the time-varying cointegration coefficients in the following regression: $e_{t}=\alpha_{1 t}\left(m_{t}-m_{t}^{*}\right)+\alpha_{2 t}\left(y_{t}-y_{t}^{*}\right)+\tilde{u}_{t}$

2. Store the estimated coefficients $\left(\hat{\alpha}_{1 t}\right.$ and $\left.\hat{\alpha}_{2 t}\right)$ and cointegration residuals $\left(\hat{u}_{t}\right)$ for each country.

3. Pairs of $\Delta\left(\mathrm{m}_{\mathrm{t}}-\mathrm{m}_{\mathrm{t}}^{*}\right)$ and $\Delta\left(\mathrm{y}_{\mathrm{t}}-\mathrm{y}_{\mathrm{t}}^{*}\right)$ are drawn randomly with replacement.

4. Construct pseudo relative money supply $\left(m_{t}-m_{t}^{*}\right)$ and relative income $\left(y_{t}-y_{t}^{*}\right)$ by cumulatively adding the randomly drawn pairs of $\Delta\left(m_{t}-m_{t}^{*}\right)$ and $\Delta\left(y_{t}-\right.$ $\left.y_{t}^{*}\right)$.

5. Estimate the $\operatorname{AR}(1)$ coefficient and residuals for $\hat{u}_{t}=\rho \hat{u}_{t-1}+\epsilon_{t}$ of each country.

6. Construct pseudo $\tilde{u}_{t}$ using $\hat{\rho}$ and randomly drawn $\hat{\epsilon}_{t}$.

7. Using $\hat{\alpha}_{1 t}, \hat{\alpha}_{2 t}$, pseudo $\left(m_{t}-m_{t}^{*}\right)$, pseudo $\left(y_{t}-y_{t}^{*}\right)$, and pseudo $\tilde{u}_{t}$, construct pseudo exchange rates for each country.

8. Using the pseudo exchange rate in step 7 and the pseudo fundamentals in step 4, estimate the time-varying cointegration model and compute the out-of-sample forecast errors.

9. Using the pseudo exchange rate in step 7 and the pseudo fundamentals in step 4, estimate the constant coefficient regression model and compute the out-of-sample forecast errors.

10. Repeat steps 3 - 9 and compute the mean squared forecast errors under the timevarying cointegration model and constant coefficient regression model. 
Table 1. Augmented Dickey-Fuller for $z_{t}=e_{t}-\left(\boldsymbol{m}_{t}-\boldsymbol{m}_{t}^{*}\right)+\left(y_{t}-y_{t}^{*}\right)$

\begin{tabular}{|c|c|c|c|}
\hline Country & Lag length & T-Statistic & P-value \\
\hline Canada & 6 & -1.023 & 0.744 \\
\hline Japan & 3 & -1.458 & 0.552 \\
\hline Switzerland & 3 & -1.540 & 0.511 \\
\hline UK & 0 & -0.587 & 0.869 \\
\hline
\end{tabular}

Note: The null hypothesis for the ADF test is that $z_{t}=e_{t}-\left(m_{t}-m_{t}^{*}\right)+\left(y_{t}-y_{t}^{*}\right)$ has a unit root. Lag lengths are determined by the AIC. 
Table 2. Estimates of Cointegration Coefficients and Engle-Granger Test Results

\begin{tabular}{|c|c|c|c|c|}
\hline \multirow{2}{*}{ Country } & \multicolumn{3}{|c|}{ Cointegration Coefficients } & \multirow{2}{*}{$\begin{array}{c}\text { ADF Test for } \\
\text { Residuals }\end{array}$} \\
\cline { 2 - 4 } & $e_{t}$ & $\left(m_{t}-m_{t}^{*}\right)$ & $\left(y_{t}-y_{t}^{*}\right)$ & -1.327 \\
\hline \multirow{2}{*}{ Canada } & 1 & 0.2186 & -0.9268 & \\
& & $(0.0676)$ & $(0.3433)$ & -1.1261 \\
\hline \multirow{2}{*}{ Japan } & 1 & -1.0400 & 1.8055 & -2.6848 \\
& & $(0.4125)$ & $(0.6019)$ & \\
\hline \multirow{2}{*}{ Switzerland } & 1 & 0.3415 & 1.3378 & -3.3679 \\
& & $(0.1508)$ & $(0.1008)$ & \\
\hline \multirow{2}{*}{ UK } & 1 & -0.1486 & -2.4345 & $(0.3127)$ \\
\hline
\end{tabular}

Note: $e_{t}=\alpha_{0}+\alpha_{1}\left(m_{t}-m_{t}^{*}\right)+\alpha_{2}\left(y_{t}-y_{t}^{*}\right)+u_{t}$ is run. The coefficient for $e_{t}$ is restricted as the unity. The table reports the estimates of $\alpha_{1}$ and $\alpha_{2}$ along with standard errors. Numbers in parentheses are standard errors. The ADF test statistic for $u_{t}$ is reported in the last column. The 5\% critical value for the ADF t-test is -3.768 (demeaned) from Phillips-Ouliaris (1990). 
Table 3. Johansen Cointegration Test Results

\begin{tabular}{|c|c|c|c|c|}
\hline country & Trace & p-value & Max-Eigenvalue & p-value \\
& statistic & & statistic & \\
\hline Canada & 33.59251 & 0.0737 & 23.55238 & 0.0333 \\
\hline Japan & 26.29625 & 0.3256 & 12.73796 & 0.5823 \\
\hline Switzerland & 36.31555 & 0.0377 & 21.96512 & 0.0556 \\
\hline UK & 34.10387 & 0.0652 & 17.85071 & 0.1865 \\
\hline
\end{tabular}

Note: 'No cointegration' is a null hypothesis and computation of critical values is based on MacKinnon-Haug-Michelis (1999) p-values. Lag intervals are selected by the AIC. The 5 percent critical values of Trace test and Maximum Eigenvalue test are 35.19275 and 22.29962, respectively. 
Table 4. Model Specification Tests for the Monetary Model with Time-varying Cointegration

\begin{tabular}{|c|c|c|c|c|}
\hline & Canada & Japan & Switzerland & UK \\
\hline $\begin{array}{l}\tau_{1}^{*} \text { from regression } \\
\text { with cointegrating } \\
\text { vector }[1,-1,1]^{\prime}\end{array}$ & 383530 & 485470 & 48917 & 18871 \\
\hline $\begin{array}{lc}\tau_{1}^{*} \quad \text { from } & \text { CCR } \\
\text { transformed } & \\
\text { regression } & \text { with } \\
\text { constant coefficient }\end{array}$ & 538.4799 & 1170.6 & 60.9799 & 20.2169 \\
\hline $\begin{array}{lr}\tau_{2}^{*} \quad \text { from } & \text { CCR } \\
\text { transformed } & \\
\text { regression } & \text { with } \\
\text { constant coefficient }\end{array}$ & 7.1399 & 93.478 & 0.7803 & 0.4286 \\
\hline $\begin{array}{l}\text { Bierens and Martin } \\
\text { test }\end{array}$ & 22.7630 & 41.5150 & 33.1061 & 22.6859 \\
\hline$\tau^{*}$ & 5.5653 & 1.9298 & 4.3123 & 10.4537 \\
\hline
\end{tabular}

Note: Regarding $\tau_{1}^{*}, \tau_{2}^{*}$ and the Bierens and Martin test, the null hypothesis is cointegration with constant coefficients, while the alternative hypothesis is time-varying cointegration. Regarding $\tau^{*}$, the null hypothesis is time-varying cointegration, while the alternative hypothesis is no cointegration. The 5\% critical value for the Bierens and Martin test is 21.03 . The $5 \%$ critical values for $\tau_{1}^{*}, \tau_{2}^{*}$, and $\tau^{*}$, reported in Park and Hahn (1999) or Shin (1994), are 11.07, 0.22, and 11.07, respectively. 
Table 5. Predictive Regressions: In-sample Analysis

\begin{tabular}{|c|c|c|c|c|c|}
\hline Country & $\begin{array}{c}\text { Forecasting } \\
\text { Horizon }\end{array}$ & \multicolumn{2}{|c|}{$z_{t}^{\text {TVC }} \begin{array}{c}\text { with time-varying } \\
\text { coefficients }\end{array}$} & \multicolumn{2}{c|}{$\begin{array}{c}z_{t} \text { with time-invariant } \\
\text { coefficients }\end{array}$} \\
\cline { 2 - 6 } & & $\beta_{k}$ & T-statistic & $\beta_{k}$ & T-statistic \\
\hline \multirow{4}{*}{ Canada } & $\mathrm{k}=1$ & -0.3141 & -4.9058 & -0.0296 & -1.0978 \\
\cline { 2 - 6 } & $\mathrm{k}=4$ & -1.0155 & -5.7951 & -0.1769 & -1.5663 \\
\cline { 2 - 6 } & $\mathrm{k}=8$ & -1.2792 & -4.7112 & -0.3796 & -1.7349 \\
\cline { 2 - 6 } & $\mathrm{k}=12$ & -1.4468 & -4.6356 & -0.663 & -2.1846 \\
\cline { 2 - 6 } & $\mathrm{k}=16$ & -1.116 & -3.3639 & -1.0449 & -2.8885 \\
\hline \multirow{6}{*}{ Japan } & $\mathrm{k}=1$ & -0.2472 & -4.4499 & -0.0071 & -0.5746 \\
\cline { 2 - 6 } & $\mathrm{k}=4$ & -0.9071 & -5.1812 & -0.0448 & -0.9483 \\
\cline { 2 - 6 } & $\mathrm{k}=8$ & -1.3906 & -4.82 & -0.1215 & -1.3205 \\
\cline { 2 - 6 } & $\mathrm{k}=12$ & -1.3529 & -4.1374 & -0.1984 & -1.4252 \\
\cline { 2 - 6 } & $\mathrm{k}=16$ & -1.0284 & -3.092 & -0.2593 & -1.3947 \\
\cline { 2 - 6 } & $\mathrm{k}=1$ & -0.1676 & -3.2028 & -0.0805 & -2.428 \\
\cline { 2 - 6 } & $\mathrm{k}=4$ & -0.6501 & -3.6417 & -0.3372 & -2.7741 \\
\cline { 2 - 6 } & $\mathrm{k}=8$ & -1.2412 & -4.1061 & -0.7259 & -3.3452 \\
\cline { 2 - 6 } & $\mathrm{k}=12$ & -1.2531 & -3.578 & -0.9647 & -3.311 \\
\cline { 2 - 6 } & $\mathrm{k}=16$ & -1.0212 & -2.6944 & -1.0479 & -2.9711 \\
\cline { 2 - 6 } & $\mathrm{k}=1$ & -0.134 & -2.6317 & -0.1078 & -2.8583 \\
\cline { 2 - 6 } & $\mathrm{k}=4$ & -0.4847 & -2.9689 & -0.4119 & -2.827 \\
\cline { 2 - 6 } & $\mathrm{k}=8$ & -0.9013 & -3.3078 & -0.8109 & -2.92 \\
\cline { 2 - 6 } & $\mathrm{k}=12$ & -1.2413 & -3.9969 & -1.2048 & -3.2095 \\
\cline { 2 - 6 } & $\mathrm{k}=16$ & -1.3345 & -4.006 & -1.4259 & -3.1313 \\
\hline
\end{tabular}

Note: The predictive regression we employ is given by: $e_{t+k}-e_{t}=a_{k}+\beta_{k} x_{t}+w_{t+k, t}$ where $x_{t}=z_{t}^{\mathrm{TVC}}=e_{t}-\alpha_{1 t}\left(m_{t}-m_{t}^{*}\right)-\alpha_{2 t}\left(y_{t}-y_{t}^{*}\right)$ for time-varying model while $x_{t}=z_{t}=e_{t}-\alpha_{1}\left(m_{t}-m_{t}^{*}\right)-\alpha_{2}\left(y_{t}-y_{t}^{*}\right)$ for time-invariant model. Hodrick (1992) standard errors are used to calculate t-statistics. 
Table 6. Predictive Regressions: Out-of-sample Analysis

\begin{tabular}{|c|c|c|c|c|}
\hline $\begin{array}{c}\text { Forecasting } \\
\text { Horizon }\end{array}$ & Canada & Japan & Switzerland & U.K. \\
\hline \multicolumn{5}{|c|}{ Time-varying Cointegration Model vs. Random Walk } \\
\hline $\mathrm{k}=1$ & $\begin{array}{c}-0.5837 \\
(0.7203)\end{array}$ & $\begin{array}{c}1.713 * * \\
(0.0434)\end{array}$ & $\begin{array}{c}1.2781 \\
(0.1006)\end{array}$ & $\begin{array}{c}-1.0992 \\
(0.8642)\end{array}$ \\
\hline $\mathrm{k}=4$ & $\begin{array}{c}1.016 \\
(0.1548) \\
\end{array}$ & $\begin{array}{c}0.5963 \\
(0.2755) \\
\end{array}$ & $\begin{array}{l}1.3943 * \\
(0.0816)\end{array}$ & $\begin{array}{c}1.0104 \\
(0.1561)\end{array}$ \\
\hline $\mathrm{k}=8$ & $\begin{array}{c}1.6473^{* *} \\
(0.0498)\end{array}$ & $\begin{array}{c}0.4804 \\
(0.3155)\end{array}$ & $\begin{array}{l}1.9674^{* *} \\
(0.0246)\end{array}$ & $\begin{array}{c}-0.2633 \\
(0.6038)\end{array}$ \\
\hline $\mathrm{k}=12$ & $\begin{array}{c}-0.08 \\
(0.5319)\end{array}$ & $\begin{array}{c}0.4551 \\
(0.3245)\end{array}$ & $\begin{array}{c}1.2617 \\
(0.1035)\end{array}$ & $\begin{array}{c}-0.2121 \\
(0.584) \\
\end{array}$ \\
\hline $\mathrm{k}=16$ & $\begin{array}{c}-0.6914 \\
(0.7554) \\
\end{array}$ & $\begin{array}{c}0.2175 \\
(0.4139) \\
\end{array}$ & $\begin{array}{c}0.8745 \\
(0.1909) \\
\end{array}$ & $\begin{array}{c}1.6625^{* *} \\
(0.0482)\end{array}$ \\
\hline \multicolumn{5}{|c|}{ Time-varying Cointegration Model vs.Time-invariant Model } \\
\hline $\mathrm{k}=1$ & $\begin{array}{c}-0.3482 \\
(0.6362) \\
\end{array}$ & $\begin{array}{c}2.3848 * * * \\
(0.0085)\end{array}$ & $\begin{array}{c}2.3197 * * \\
(0.0102) \\
\end{array}$ & $\begin{array}{c}-0.3776 \\
(0.6471) \\
\end{array}$ \\
\hline $\mathrm{k}=4$ & $\begin{array}{c}1.6575^{* *} \\
(0.0487)\end{array}$ & $\begin{array}{l}1.4551 * \\
(0.0728)\end{array}$ & $\begin{array}{c}2.4398 * * * \\
(0.0073)\end{array}$ & $\begin{array}{c}2.5892 * * * \\
(0.0048)\end{array}$ \\
\hline $\mathrm{k}=8$ & $\begin{array}{l}1.4369 * \\
(0.0754)\end{array}$ & $\begin{array}{c}1.1484 \\
(0.1254)\end{array}$ & $\begin{array}{c}2.8252 * * * \\
(0.0024)\end{array}$ & $\begin{array}{c}1.7228^{* *} \\
(0.0425)\end{array}$ \\
\hline $\mathrm{k}=12$ & $\begin{array}{c}1.8592^{* *} \\
(0.0315)\end{array}$ & $\begin{array}{c}0.4115 \\
(0.3403) \\
\end{array}$ & $\begin{array}{c}3.2744^{* * *} \\
(0.0005)\end{array}$ & $\begin{array}{l}1.8903^{* *} \\
(0.0294) \\
\end{array}$ \\
\hline $\mathrm{k}=16$ & $\begin{array}{l}1.3653 * \\
(0.0861)\end{array}$ & $\begin{array}{c}-0.0085 \\
(0.5034)\end{array}$ & $\begin{array}{c}3.5211 * * * \\
(0.0002)\end{array}$ & $\begin{array}{c}2.0584^{* *} \\
(0.0198)\end{array}$ \\
\hline
\end{tabular}

Note: Out-of-sample predictions are formed based on the following regressions: $e_{t}=\alpha_{0}+\alpha_{1 t}\left(m_{t}-m_{t}^{*}\right)+\alpha_{2 t}\left(y_{t}-y_{t}^{*}\right)+u_{t}$ and $e_{t+k}-e_{t}=a_{k}+\beta_{k} z_{t}^{T V C}+w_{t+k, t}$, where $z_{t}^{T V C}=e_{t}-\alpha_{1 t}\left(m_{t}-m_{t}^{*}\right)-\alpha_{2 t}\left(y_{t}-y_{t}^{*}\right)$. Based on the first equation, we first estimate time-varying parameters $\alpha_{1 t}, \alpha_{2 t}$, and then $z_{t}^{T V C}$ with data up to time $t_{0}$. Next, we estimate the second equation via the OLS method using the estimated $\left\{z_{t}^{T V C}\right\}_{t=1}^{t_{0}-k}$. Finally, we make a forecast of $\widehat{e_{t_{0}+k}}-e_{t_{0}}$ with the use of estimated $z_{t_{0}}^{T V C}$ and the estimates of $a_{k}$ and $\beta_{k}$. Next, we repeat these steps to predict $\widehat{e_{t_{0}+k+1}}-e_{t_{0}+1}$, after adding the observations of the exchange rate and fundamentals at $t_{0}+1$ and removing the oldest observations to keep the window size fixed. The initial forecasting point starts from the second quarter of 1991, which is the middle point of our sample. The Clark-West test statistics (Clark and West (2007)) are used to compare forecast ability. A significant positive value of the Clark-West test statistics indicates that the second model (the predictive regression with $z_{t}^{T V C}$ ) is superior to the first model (the random walk model without drift or the predictive regression with $\left.z_{t}=e_{t}-\alpha_{1}\left(m_{t}-m_{t}^{*}\right)+\alpha_{2}\left(y_{t}-y_{t}^{*}\right)\right)$ in predictive ability. Numbers in parenthesis are p-values. ' ${ }^{\prime},{ }^{\prime}{ }^{\prime} * *^{\prime}$, and ${ }^{\prime} * * *^{\prime}$ denote the significance level at the $10 \%, 5 \%$, and $1 \%$ level for a one-tail test, respectively. 
Table 7. Mean Squared Forecast Errors under a Time-varying Cointegration Process: Time-varying model vs. Linear model

\begin{tabular}{|c|c|c|c|c|}
\hline $\begin{array}{c}\text { Forecasting } \\
\text { Horizon }\end{array}$ & Canada & Japan & Switzerland & U.K. \\
\hline $\mathrm{k}=1$ & 1.11 & 1.1674 & 1.081 & 1.1829 \\
\hline $\mathrm{k}=4$ & 0.8981 & 0.971 & 0.8721 & 0.9368 \\
\hline $\mathrm{k}=8$ & 0.7007 & 0.7849 & 0.6755 & 0.8386 \\
\hline $\mathrm{k}=12$ & 0.6315 & 0.7137 & 0.6763 & 0.8859 \\
\hline $\mathrm{k}=16$ & 0.6243 & 0.6849 & 0.7407 & 0.9493 \\
\hline
\end{tabular}

Note: This table reports the ratio of the MSFE of time-varying coefficient model relative to the MSFE of the constant coefficient model, using data generated by the model. For each currency, 1000 simulations for out-of-sample forecasting exercise are conducted over the 151quarter samples corresponding to 1973. II - 2010. IV historical data. Out-of-sample forecasting is implemented in the same way as described in sub-section 4. 2. Then, mean squared forecast errors of both models are calculated. 
Table 8. Directional Accuracy Test

\begin{tabular}{|c|c|c|c|c|c|}
\hline $\begin{array}{c}\text { Forecasting } \\
\text { Horizon }\end{array}$ & Canada & Japan & Switzerland & U.K. \\
\hline \multirow{4}{*}{$\mathrm{k}=1$} & Proportion & 0.4430 & 0.5443 & 0.4937 & 0.4051 \\
\cline { 2 - 6 } & Test & -1.0126 & 0.7876 & -0.1125 & -1.6876 \\
& statistics & $(0.1556)$ & $(0.2155)$ & $(0.4552)$ & $(0.0457)$ \\
\hline \multirow{4}{*}{$\mathrm{k}=4$} & Proportion & 0.4737 & $0.6053^{* *}$ & 0.5263 & 0.4605 \\
\cline { 2 - 6 } & Test & -0.4588 & 1.8353 & 0.4588 & -0.6882 \\
& statistics & $(0.3232)$ & $(0.0332)$ & $(0.3232)$ & $(0.2456)$ \\
\hline \multirow{3}{*}{$\mathrm{k}=8$} & Proportion & $0.6806^{* * *}$ & 0.5278 & $0.6389^{* * *}$ & $0.5972^{* *}$ \\
\cline { 2 - 6 } & Test & 3.0641 & 0.4714 & 2.3570 & 1.6499 \\
& statistics & $(0.0011)$ & $(0.3187)$ & $(0.0092)$ & $(0.0495)$ \\
\hline \multirow{3}{*}{$\mathrm{k}=12$} & Proportion & $0.6176^{* *}$ & 0.5000 & $0.6471^{* * *}$ & 0.5735 \\
\cline { 2 - 6 } & Test & 1.9403 & 0.0000 & 2.4254 & 1.2127 \\
& statistics & $(0.0262)$ & $(0.5000)$ & $(0.0076)$ & $(0.1126)$ \\
\hline \multirow{3}{*}{$\mathrm{k}=16$} & Proportion & 0.5469 & 0.5156 & $0.5938^{*}$ & $0.6406^{* *}$ \\
\cline { 2 - 6 } & Test & 0.7500 & 0.2500 & 1.5000 & 2.2500 \\
& statistics & $(0.2266)$ & $(0.4013)$ & $(0.0668)$ & $(0.0122)$ \\
\hline
\end{tabular}

Note: 'Proportion' denotes the proportion of forecasts that predict correctly directional changes in the exchange rate based on the monetary model with time-varying cointegration coefficients. Numbers in parentheses are p-values for the null hypothesis that the proportion is significantly different from $1 / 2 .^{18}{ }^{\prime} *^{\prime},{ }^{\prime} * *^{\prime}$, and ${ }^{\prime} * * *^{\prime}$ denote the significance level at the $10 \%, 5 \%$, and $1 \%$ level, respectively.

\footnotetext{
${ }^{18}$ A left-sided 5\% significance test may contain important information like inverse correlation. However, only a right-sided 5\% significance test is considered since we are seeking evidence that the directional movements of our forecasts keep in step with the actual movements in the exchange rate as Fujiwara and Koga (2004) mentioned.
} 
Figure 1. Time-varying Cointegration Coefficients for $\left(m_{t}-m_{t}^{*}\right)$
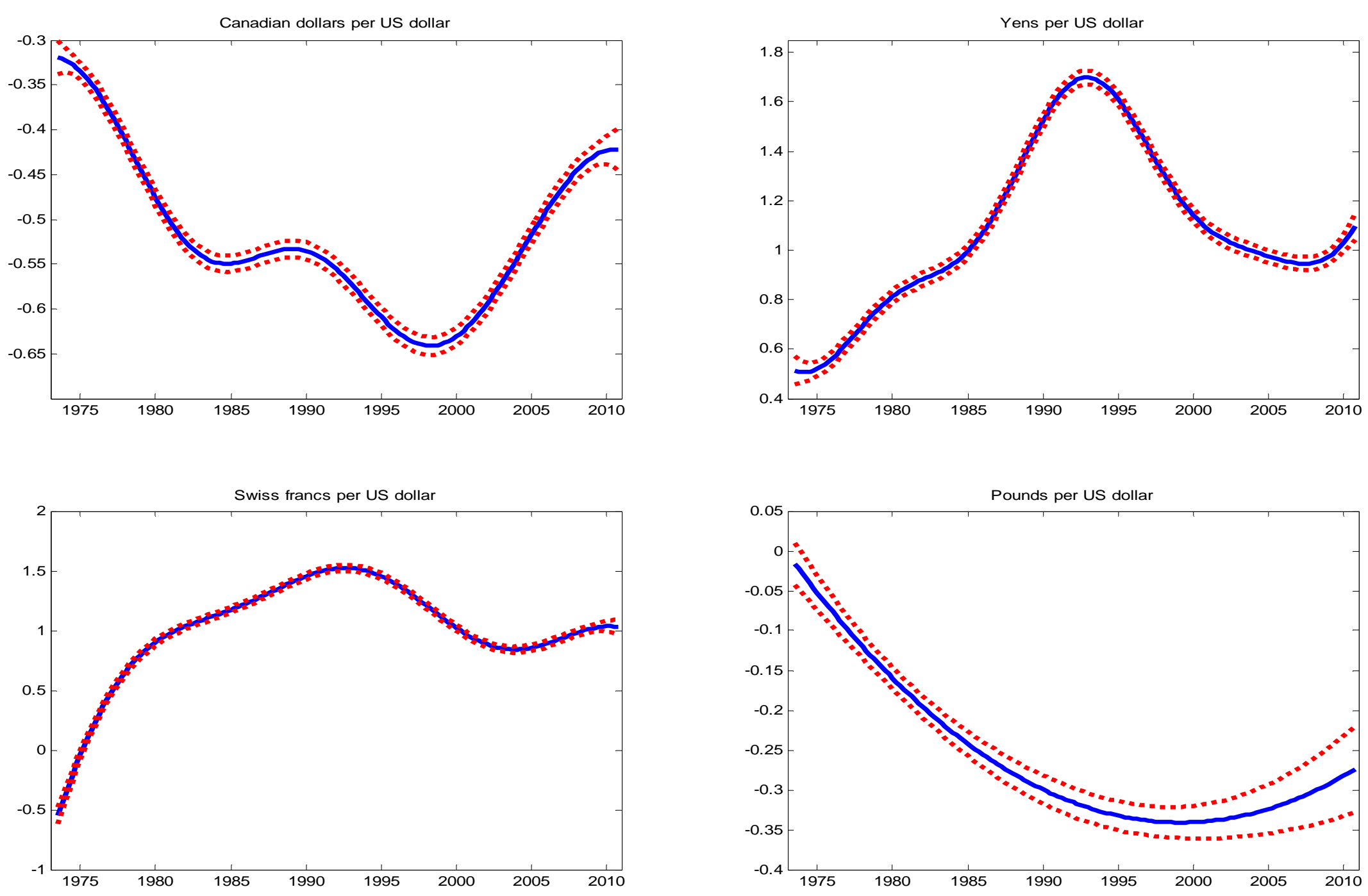
Figure 2. Time-varying Cointegration Coefficients for $\left(y_{t}-y_{t}^{*}\right)$
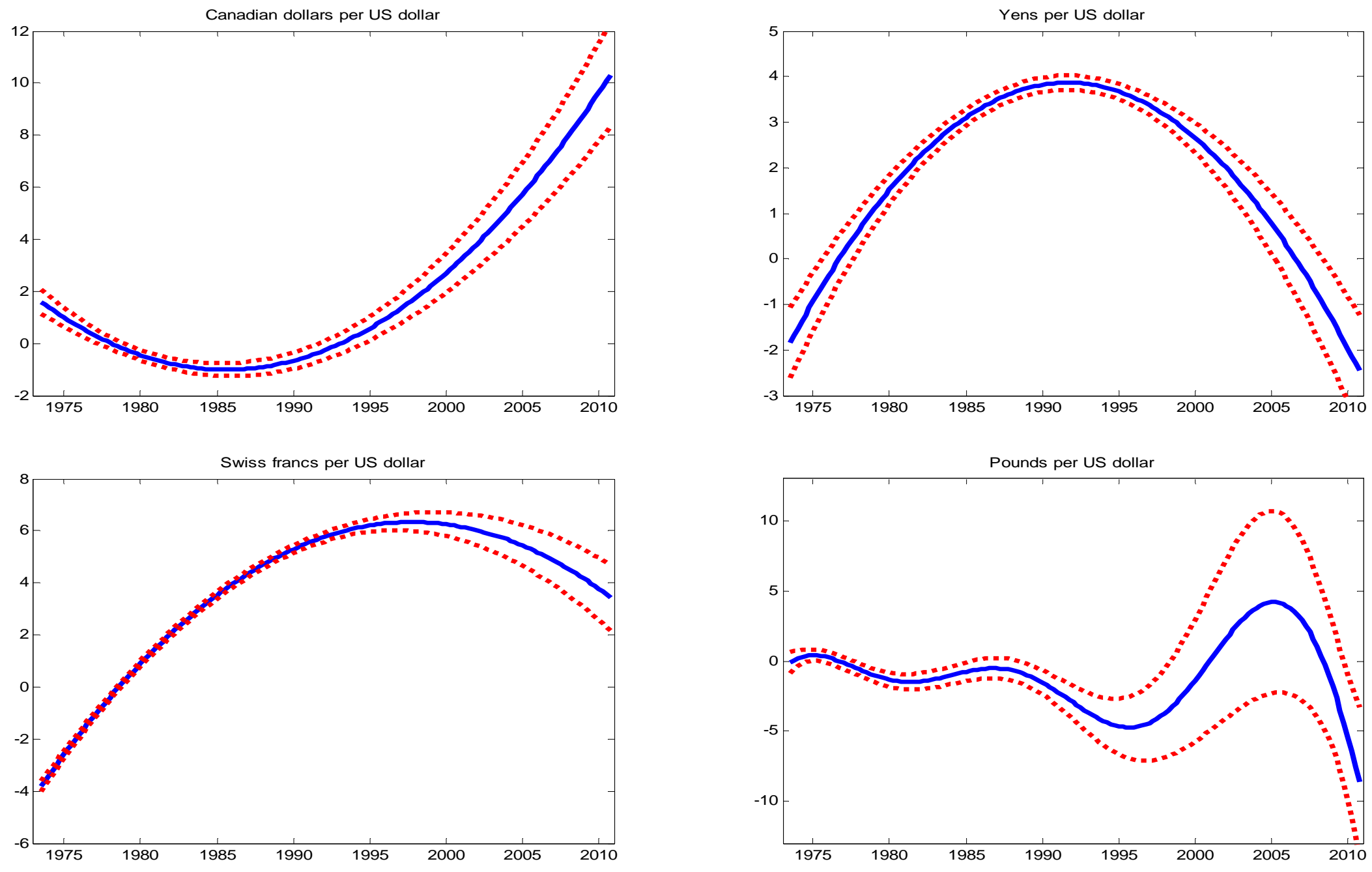

38 
Figure 3. Demeaned regression Errors with [ $\left[\begin{array}{lll}1 & -1 & 1\end{array}\right]$ vs. Demeaned Cointegration Errors with Time-varying Coefficients
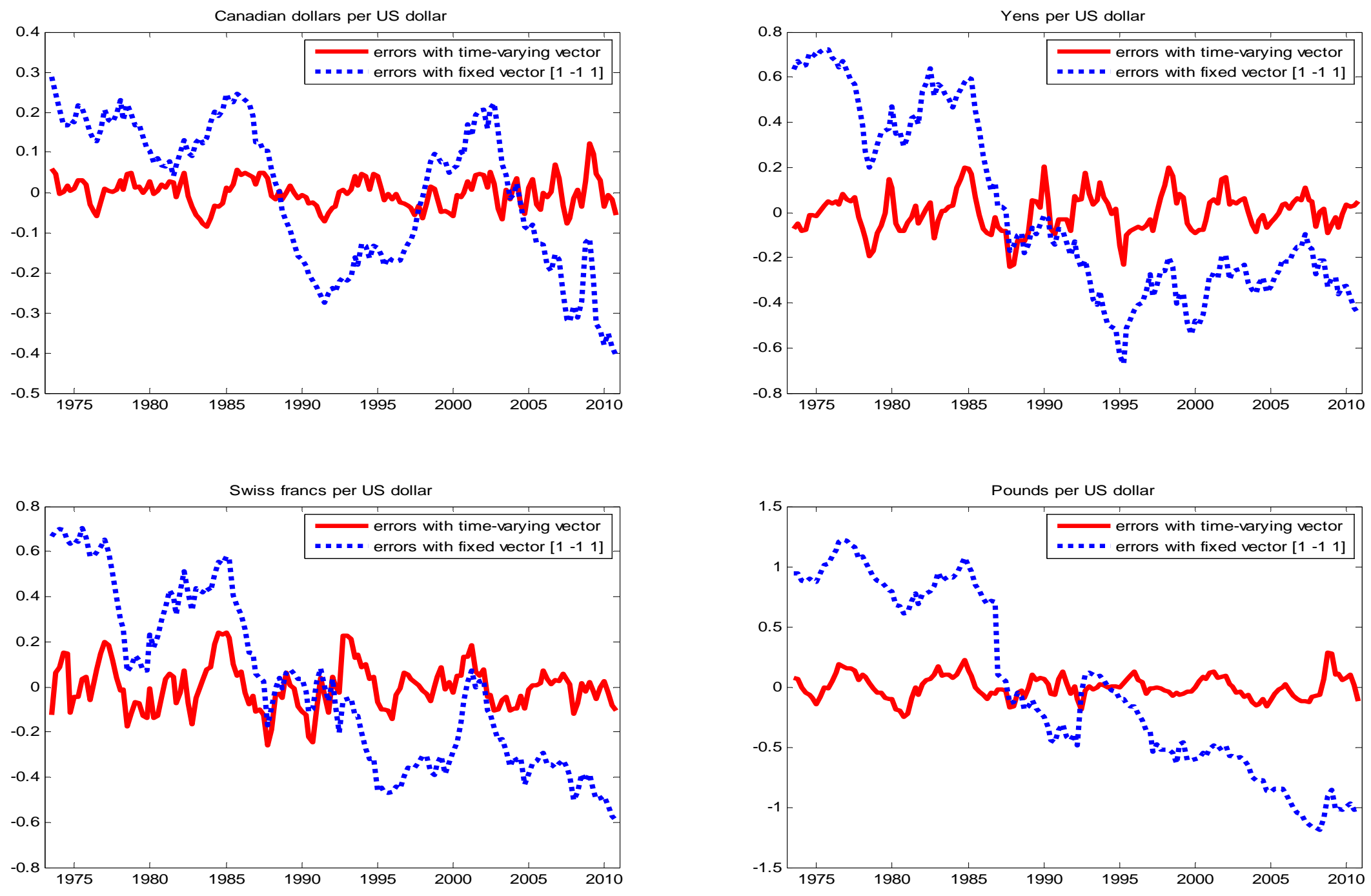